\title{
Influencing Carbon Behaviours: What Psychological and Demographic Factors Contribute to Individual Differences in Home Energy Use Reduction and Transportation Mode Decisions?
}

\author{
Clare Hall ${ }^{1} \&$ Fraser Allan ${ }^{1}$ \\ ${ }^{1}$ Land Economy, Environment and Society Research Group, SRUC, United Kingdom \\ Correspondence: Clare Hall, Environment and Society Research Group, Land Economy, SRUC, United \\ Kingdom. Tel: 44-131-535-4124. E-mail: clare.hall@sruc.ac.uk
}

Received: December 3, 2013 Accepted: December 23, 2013 Online Published: January 6, 2014

doi:10.5539/eer.v4n1p1

URL: http://dx.doi.org/10.5539/eer.v4n1p1

\begin{abstract}
As pressure mounts on countries to reduce carbon emissions, there is increasing interest in understanding what drives "carbon behaviours", in order to inform behavioural change policies. This study examined the impact of psychological and demographic variables, on "carbon behaviours". Secondary data analysis was carried out to investigate the antecedents of residential energy use reduction behaviours and choice of transportation mode for commuting and grocery shopping. Models explained $18.2 \%$ and $25.2 \%$ of variance in energy use and transport behaviours respectively. Being concerned about climate change and having an environmental identity increased household energy reduction behaviour but did not significantly affect travel mode choices. The antecedents of travel mode decisions were attitudes towards the travel mode itself, and demographic and structural variables such as income and distance travelled. Findings suggest that using "green" messaging will help encourage behavioural change in energy use, but contribute little to encouraging change in travel mode decisions.
\end{abstract}

Keywords: low carbon behaviours, energy use, travel mode, climate change, Scotland

\section{Introduction}

There is broad international acknowledgment that climate change, occurring as a result of human behaviours, is causing damage to the environment and is affecting ecological systems such as ocean currents and weather patterns (Parry et al., 2007). In order to stabilise global temperatures at levels which would limit the worst impacts, greenhouse gas (GHG) emissions must be reduced (Stern, 2006). Two sectors which make up a large proportion of global GHG emissions are household energy use and road transport. For example, emissions from household energy use are responsible for roughly $23 \%$ of GHG emissions in the UK (Palmer \& Cooper, 2011), while emissions from passenger cars, buses, mopeds, and motorcycles account for around 13\% (Department of Energy and Climate Change, 2012).

This means that reducing household energy use, and the use of GHG intensive transport, has an important part in lowering GHG emissions. These are both actions over which most people have direct control (Stead, 2007; Dijst et al., 2008), and thus offer a meaningful way for citizens to engage in GHG emission reduction. Governments recognise the important role that these kinds of voluntary behavioural changes have to play in reducing GHG emissions (see for example, Cabinet Office Behavioural Insights Team, 2011; Scottish Government, 2010). While this seeks to circumvent the need to impose regulatory restrictions on individuals, it still leaves a role for government in providing the necessary incentives and enablers. Thus governments need evidence of what influences peoples' behaviours. By way of illustration, at UK level, the Department of Energy and Climate Change began, in 2012, to collect data through a public attitudes tracker survey (DECC, 2013). This includes questions about attitudes to climate change.

While such data may help inform policy on how to meet emissions targets through behavioural change in the UK, the overall policy situation is somewhat complicated by devolution. The Scottish government passed the Climate Change (Scotland) Act 2009, setting targets for reducing GHG emissions by $42 \%$ by 2020 (higher than the rest of the UK) and $80 \%$ by 2050, from a baseline year of 1990 for carbon dioxide $\left(\mathrm{CO}_{2}\right)$ and 1990 or 1995 for other GHGs (Scottish Parliament, 2009) (Note 1). Thus Scotland presents an interesting case study through which to consider potential barriers to, and facilitators of, behavioural change relevant to achieving a lower carbon future. 
Accordingly, this study uses data from a Scotland-wide survey to investigate how factors including attitudes to climate change, knowledge of climate change, and environmental identity relate to energy and travel behaviours. The remainder of this paper is structured as follows: the next section presents a review of models explaining how psychological and demographic factors affect behaviour, and an overview of empirical evidence from previous studies. Following that, the approach used in the present study is described, and results from the analysis are presented and discussed in relation to the existing theory and knowledge. The paper concludes with some recommendations and implications relating to how to motivate behavioural change in order to meet emission reduction targets.

\subsection{Behavioural Models}

The Theory of Planned Behaviour (TPB) (Ajzen, 1991) is a conceptual psychological framework for explaining why people undertake behaviour, which built on the Theory of Reasoned Action (TRA) proposed by Fishbein and Ajzen (1975). In its simplest form the TPB postulates that there are three determinants of a person's intention to perform an action: attitudes, subjective norms, and perceived behavioural control (PBC). Attitudes are the extent of favourable or unfavourable assessment of a particular behaviour (not the object of the behaviour) (Ajzen, 1991), while subjective norms are the degree to which a person believes "important others" would approve or disapprove of a given course of action (Fishbein \& Ajzen, 1975). PBC is included as a determinant of intention because a perception of lack of control can form a real barrier (Dijst et al., 2008). PBC also acts directly on behaviour as a proxy for actual control (Fielding et al., 2008), based on a general assumption that perceived and actual control are highly correlated (Dijst et al., 2008).

It is now widely accepted that the TPB model has predictive limitations due to its generality, and in practice the majority of studies use additional determinants outside of the limitations originally envisaged (Armitage \& Conner, 2001). Using additional context dependent variables can increase the explanatory power of the model (Fielding et al., 2008). Extensions have included Knowledge, typically added where it can be operationalised objectively (Fielding et al., 2008). Identity can be incorporated as a view of the self, where acting in a manner in accordance with one's identity gives a sense of validation, while acting contrary to it leads to inner tension (Fielding et al., 2008) (Note 2). Prioritisation of goals relates to the importance placed on different desired end results separate from the immediate outcome of the behaviour, and can also be important (Dijst et al., 2008; Sheppard et al., 1988).

Including both psychological and demographic factors typically explains a larger share of the variance, or spread in the data, than using one or the other alone (Fujii \& Gärling, 2003; Dijst et al., 2008). Social scientists have tended to focus on how internal processes (e.g., values) affect behaviour, whereas economists tend to focus on external factors such as taxes or legislation (Guagano et al., 1995). Using demographic information as the sole source of prediction of behaviour implies that behaviour is constant as long as one's circumstances do not change, so that changing attitudes or emotions would have no effect (Dijst et al., 2008). To address this, Guagano et al. (1995) proposed their "ABC model" - which considers the effects of attitudes (A) and context (C) on behaviour (B). They suggested that the effects of different factors on behaviour are not necessarily constant, and that inclusion of both attitude and context variables, and the interaction between them, is needed to expand the predictive usefulness of behavioural models.

\subsection{The Influence of Psychological Factors on Environmental Behaviours}

This overview considers literature on energy use and transport behaviours, as well as environmental behaviours in general, to allow that environmentally driven behaviours may share underlying psychological determinants.

As discussed, attitudes are one of the fundamental determinants of intent and behaviour in many psychological models (Ajzen, 1988; Guagano et al., 1995). Environmental attitudes can have significant impacts on intention to engage in environmental activism (Fielding et al., 2008), and other psychological drivers such as identity can affect residential energy use decisions, particularly where personal and societal interests are in conflict (Poortinga et al., 2004).

Positive environmental attitudes have been associated with increases in support for government regulation of the environment (Poortinga et al., 2004), a readiness to take action against environmentally unfriendly companies, and willingness to pay taxes to protect forests (Stern et al., 1995).

Prioritising the environment relative to other concerns has been shown to have a positive effect on recycling behaviour, environmental stewardship and public activism (Huddart-Kennedy et al., 2009). Similarly, the importance a person places on climate change increases their propensity to engage in domestic energy conservation on a regular basis (Whitmarsh \& O'Neill, 2010). Individuals who prioritise climate change are also 
more likely to engage in low carbon activities and lifestyles (Whitmarsh et al., 2011), and to engage in multiple types of environmental behaviours (Stern, 2000).

Identifying oneself with a particular group can lead to accentuating similarities (or differences) with those who are (or are not) members of the same group (Fielding et al., 2008). Having an environmental identity has been found to be a positive predictor of home energy conservation in the UK (Whitmarsh \& O'Neill, 2010). Identity may also affect behaviour "in cases where our role identity dictates we behave in a certain way, irrespective of how we feel about that behaviour" (Whitmarsh \& O'Neill, 2010). Social norms also impact on intent to engage in low-carbon purchasing and low-carbon energy use (Lingyun et al., 2011), and environmental activism (Fielding et al., 2008).

\subsection{The Influence of Demographic Factors on Environmental Behaviours}

Actual energy use tends to decrease with education level ceteris paribus, though education is highly correlated with income, which has a larger positive effect on energy use (Poortinga et al., 2004). Taken together, this suggests that when comparing two people on similar incomes, those with more education will, on average, use less energy. However, in other cases, education has not been found to be related to energy saving (Paço \& Varejão, 2010; Neuman, 1986). Further, one survey of the UK public found that qualifications were a significant factor contributing to reduced energy conservation in the home (Whitmarsh \& O'Neill, 2010). Thus the impact of education level on energy use behaviours is unclear.

Household income has been found to have a positive relationship with both environmental knowledge, and environmental behaviour (Jones et al., 1999). Income has been positively related to knowledge of climate change, but more strongly positively linked to self-reported knowledge of climate change (McCright, 2010). Similarly, though residential energy use increases with income, it is still possible to expect higher income to be linked to higher reported energy saving behaviour (McCright, 2010).

However, the expected correlation between income and education (Stead, 2007) can make it difficult to draw robust conclusions regarding the effect of one or the other depending on the form of the model.

Greater knowledge of the environment can increase uptake of actions to reduce a person's impact on the environment (Grob, 1995). For recycling behaviour, awareness of the environmental consequences of not recycling increases awareness of personal responsibility, which in turn has a measureable effect on actual behaviour, suggesting an indirect hierarchical effect (Guagano et al., 1995). Similarly, increased knowledge of climate change has been found to relate significantly to increased concern about the effects of climate change (McCright, 2010), which was found to affect behaviour.

Age has been found to be correlated with higher actual energy use (Poortinga et al., 2004), but negatively related to both actual and self-reported climate change knowledge (McCright, 2010). Willingness to pay more for environmentally friendly products increases slightly with age (Lynn \& Longhi, 2011). Home energy use behaviours, such as always turning off lights when leaving the room, may be more prevalent as age increases (Lynn \& Longhi, 2011). However some studies have found no impact of age on either knowledge, or environmental behaviour (Jones et al., 1999).

Women have been found to be more knowledgeable about climate change, and marginally more concerned about its effects (McCright, 2010), though not all studies found statistical significance. Women are also more likely to change their behaviour towards a company for environmental reasons (Stern et al., 1995), and exhibit slightly better energy saving behaviour in the home (Paço \& Varejão, 2010). However men are more likely to report having increased their use of public transport and reduced their fuel use (Stead, 2007).

Energy use increases predictably with the number of people in the household (Poortinga et al., 2004), and those with dependent children are significantly less likely to be willing to pay more for environmental products (Lynn \& Longhi, 2011). However, the number of adults in the household has been shown to have no effect on home energy conservation behaviours (Whitmarsh \& O’Neill, 2010).

Urban residents may be more likely to be aware of environmental problems, to consider them important, and to take action to reduce their impact (Jones et al., 1999). However, emphasis on issues which are more significant in urban area (e.g., air and noise pollution), which assess services which may not be provided in areas with low population density (e.g., recycling or public transport), or which fail to address demographic differences can result in bias (Jones et al., 1999; Berenguer et al., 2005). Studies which balance rural and urban environmental issues have found that levels of environmentalism are similar in both (Huddart-Kennedy et al., 2009). However differences do exist, with findings that rural residents are more knowledgeable about the environment in general (Jones et al., 1999), more concerned with environmental conservation (Berenguer et al., 2005), and place more 
importance on stewardship of the environment (Huddart-Kennedy et al., 2009). On the other hand, urban residents have more pro-environmental attitudes, more frequently engage in pro-environmental behaviours (Berenguer et al., 2005), and are more likely to regularly engage in domestic energy conservation (Whitmarsh \& O’Neill, 2010).

Demographic factors which affect behaviours directly have also been found in certain situations to act indirectly on behaviours, presenting hierarchical effects. Thus even where there is no direct effect, their influence may still be important. For example, education has been positively linked to climate change knowledge (Jones et al., 1999), and self-reported knowledge (McCright, 2010), which may in turn affect behaviour. It has also been found to relate to intention to reduce fuel use in the future and to increase the use of public transport (Stead, 2007), as well as being related to undertaking more environmental behaviour (Jones et al., 1999).

Overall, the evidence on the influence of demographic factors on environmental behaviours is largely inconclusive, supporting the need for additional consideration of psychological factors such as attitudes.

\section{Methods}

The research reported here is from secondary data analysis that investigated the antecedents of energy use reduction in the home and choice of transportation mode used for commuting and grocery shopping. The data used in this study comes from the Scottish Environmental Attitudes and Behaviours Survey (SEABS) (Davidson et al., 2009).

\subsection{The Respondent Sample}

The data was collected from interviews, generating cross-section data $(n=3,054)$ that is largely representative of the Scottish population. Respondents who did not fill in a self-completion part of the survey investigating attitudes, and those who did not reveal their income or their level of education were removed from the sample used for the present analysis (Note 3). The remaining sample $(n=1,877)$ had 944 males $(50.3 \%)$ and 933 females $(49.1 \%)$, aged between 16 and 92, with a mean age of 47.1 years $(S . D .=17.3) .40 .6 \%$ of respondents were employed full time, $23.0 \%$ were permanently retired, and $4.6 \%$ were students (Table 1 ).

Table 1. Socio-demographic variables

\begin{tabular}{|c|c|c|}
\hline Variable & Categories & $\begin{array}{c}\text { Percentage of } \\
\text { respondents }\end{array}$ \\
\hline \multirow[t]{5}{*}{ Age } & $16-24$ & 10.2 \\
\hline & $25-34$ & 16.8 \\
\hline & $35-54$ & 41.0 \\
\hline & $55+$ & 31.8 \\
\hline & Refused & 0.1 \\
\hline \multirow[t]{2}{*}{ Sex } & Male & 50.3 \\
\hline & Female & 49.7 \\
\hline \multirow[t]{6}{*}{ Household income } & Under $£ 10,000$ & 20.8 \\
\hline & $£ 10,000-£ 19,999$ & 24.5 \\
\hline & $£ 20,000-£ 29,999$ & 16.4 \\
\hline & $£ 30,000-£ 39,999$ & 13.6 \\
\hline & $£ 40,000-£ 49,999$ & 8.8 \\
\hline & $£ 50,000$ or more & 16.0 \\
\hline \multirow[t]{8}{*}{ Employment Status } & Employed full time & 40.6 \\
\hline & Employed part time & 9.0 \\
\hline & Self employed & 5.1 \\
\hline & Unemployed & 5.0 \\
\hline & School/further education & 4.6 \\
\hline & Permanently retired & 23.0 \\
\hline & Stay at home & 7.2 \\
\hline & Other & 5.5 \\
\hline \multirow[t]{5}{*}{ Highest level of qualification obtained } & Degree, professional & 31.0 \\
\hline & $\mathrm{HNC} / \mathrm{HND}$ or equivalent & 9.3 \\
\hline & A, Higher, or equivalent & 15.2 \\
\hline & $\mathrm{O}$, Standard or equivalent & 24.9 \\
\hline & None & 19.6 \\
\hline
\end{tabular}




\begin{tabular}{llc} 
How many children or babies are there in your & None & 67.7 \\
household, aged under 16? & One & 15.1 \\
& Two & 12.6 \\
& Three & 3.3 \\
& Four or more & 1.3 \\
Including yourself how many adults are there in & One & 28.9 \\
your household, aged 16+? & Two & 53.3 \\
& Three & 12.8 \\
\hline Dwelling type & Four or more & 5.0 \\
\hline
\end{tabular}

An additional variable was included from the Scottish Household Survey (Scottish Government, 2011). This gave the percentage of the population in a datazone (a small region of between 500 and 1000 households) living near a high frequency bus service (one running five or more times an hour). The average percentage of the population of a datazone living near to a high frequency bus service was $32.2 \%$. The minimum population percentage was $7.5 \%$ and the maximum was $59.3 \%$.

\subsection{Operationalisation of The Variables}

\subsubsection{The Behaviours}

The SEABS dataset included the frequency of engagement with five energy use behaviours: turning down the heating when going out in winter, using energy-saving light bulbs, hanging washing out to dry in summer, turning lights off in unused rooms, and not overfilling the kettle. Responses ranged from "never" to "always".

To assess peoples' transport mode choices, respondents indicated their primary mode of transport to their place of work or study, and for grocery shopping. Responses were grouped into four categories (walk/cycle, public transport, multiple passenger, and single driver) to create an ordinal scale positive in more carbon intensive modes (adapted from Arnold, 2010).

Both energy use behaviour and choice of travel mode were tested as combined scales, and additionally as individual behaviours/travel mode to see if underlying factors differed between energy behaviours/travel modes, and to verify how well the scales captured the overall effects.

\subsubsection{Attitudes, Importance and Identity}

Attitudinal scales were derived from multiple Likert scale responses to related statements with responses ranging from 'strongly disagree' to 'strongly agree', which were recoded between " -2 " and " +2 ".

A scale measuring attitudes to climate change was made up of nine statements which addressed climate change, environmental crisis, or household energy use, and one additional question which asked respondents which of four statements most closely reflected their views on climate change, with responses ranging from disbelief to urgency. Responses were recoded to be positive in increasing concern for climate change.

Attitudes towards travel modes were assessed from responses to statements regarding whether car use is necessary, if it is a right, and the reliability and convenience of public transport. These were recoded such that responses which were pro-car or negative towards public transport were positive.

Respondents were also asked how important it is that everyone in Scotland perform each of the household energy use reduction behaviours. Responses were scored on a five-point Likert scale ranging from "not at all important" to "very important" and were recoded and summed to create a scale measuring the perceived importance of household energy use reduction behaviour.

A variable was constructed to measure environmental identity based on the extent of respondents' discussions with others about the environment, promotion of behavioural change in others, and whether they are members of, or make regular donations to, environmental or land based charities.

Other factors included in the analysis were a mix of variables from SEABS and some specifically constructed for this analysis, designed to incorporate relevant psychological and demographic antecedents of behaviour. For example variables were included to test the effect of knowledge and residential location. 


\subsection{The Model}

Based on the psychological literature and empirical findings examined, it was anticipated that hierarchical effects would exist, with psychological variables being influenced by demographic variables, and both affecting behaviour. A four-tiered model was hypothesised, with each tier affecting those below it (Figure 1). Secondary analysis was performed by testing the model by means of a multi-stage ordinary least squares (OLS) regression.

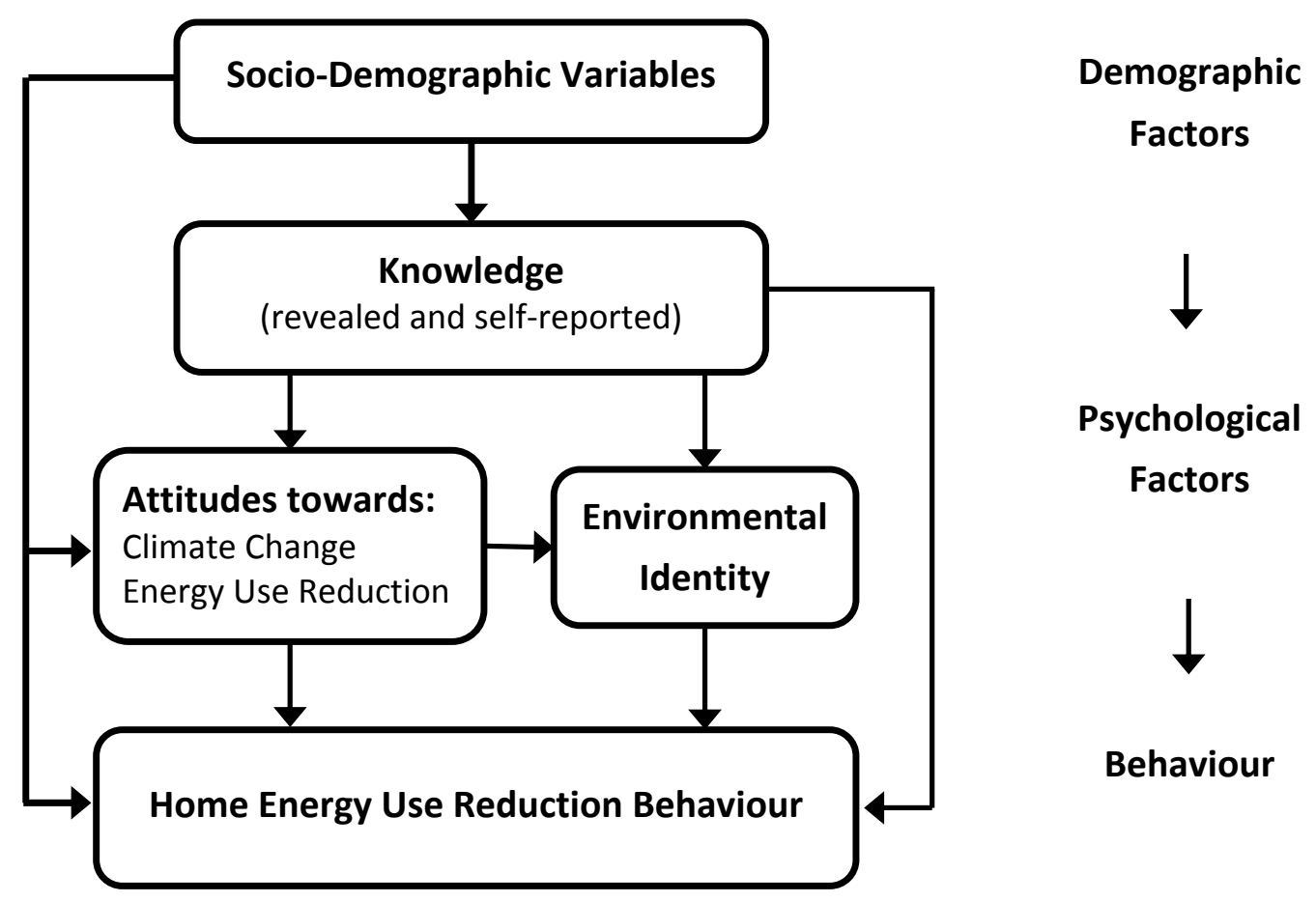

Figure 1. Model of hierarchical determinants of energy use reduction behaviour (A similar model was constructed for travel mode decisions for commuting and grocery shopping)

\section{Results}

\subsection{Home Energy Use Reduction Behaviours}

The model accounted for $18.2 \%$ of the variance in the home energy use reduction behaviours (Table 2, Adj $\mathrm{R}^{2}=$ 0.182). Having an attitude of concern for climate change and having an environmental identity were positively related to energy use reduction behaviours. Greater revealed knowledge of climate change was found to have a significant impact on attitude to climate change and attitude to energy use reduction, but not behaviour directly. Self-reported knowledge was found to have a positive effect on attitudes, environmental identity, and energy use reduction behaviours. Prioritisation of climate change by respondents had no direct effect on behaviour, but had a significant positive effect on both environmental identity and concern for climate change.

Household income was found to have a significant negative effect on energy reduction behaviours, but no impact on attitude or identity. Contrastingly, educational achievement was non-significant for behaviour but had a positive coefficient impact on attitudes and increased the likelihood of having an environmental identity. Being female was found to have a direct positive effect on energy use reduction behaviours and attitudes to climate change. The number of children in the household was found to have a significant negative effect on the propensity to engage in energy use reduction behaviours. Other results were that students had lower performance of household energy reduction behaviours, and being in receipt of cold-weather benefit payments had a significant positive effect on household energy reduction behavior (Note 4). 
Table 2. Home energy use results

\begin{tabular}{|c|c|c|c|c|c|c|c|c|}
\hline \multirow{3}{*}{$\begin{array}{l}\text { Independent Variables } \\
\text { (Range) [Units] } \\
\text { Environmental identity }(0: 10)\end{array}$} & \multicolumn{8}{|c|}{ Dependent variable $(n=1,875)$} \\
\hline & \multicolumn{2}{|c|}{$\begin{array}{l}\text { Energy use } \\
\text { reduction }\end{array}$} & \multicolumn{2}{|c|}{$\begin{array}{l}\text { Environ. } \\
\text { identity }\end{array}$} & \multicolumn{2}{|c|}{$\begin{array}{c}\text { Attitude to } \\
\text { climate } \\
\text { change }\end{array}$} & \multicolumn{2}{|c|}{$\begin{array}{c}\text { Attitude to } \\
\text { energy use } \\
\text { reduction }\end{array}$} \\
\hline & 0.036 & $*$ & & & & & & \\
\hline Attitude to climate change $(-1.9: 2)$ & 0.040 & & 0.409 & $* *$ & & & & \\
\hline Attitude to energy use reduction $(-2: 2)$ & 0.030 & $*$ & 0.043 & $*$ & & & & \\
\hline Revealed knowledge $(-3: 15)$ & 0.013 & & 0.009 & & 0.068 & $* *$ & 0.029 & $*$ \\
\hline Self-reported knowledge (-2:2) & 0.057 & $*$ & 0.265 & $* *$ & 0.165 & $* *$ & 0.151 & $* *$ \\
\hline Prioritisation of climate change $(0: 4)$ & & & 0.104 & $* *$ & 0.132 & $* *$ & 0.056 & $*$ \\
\hline Importance of energy behaviours $(-2: 2)$ & 0.414 & $* *$ & & & & & & \\
\hline Age $(16: 92)$ & 0.002 & & 0.016 & & 0.020 & $* *$ & 0.030 & $* *$ \\
\hline Age squared + & 0.000 & & 0.000 & & 0.000 & $* *$ & 0.000 & $* *$ \\
\hline Female $(0: 1)$ & 0.073 & $*$ & -0.009 & & 0.154 & $* *$ & 0.050 & \\
\hline Number of adults $(1: 4)$ & -0.018 & & -0.008 & & -0.010 & & 0.009 & \\
\hline Number of children $(0: 4)$ & -0.042 & $*$ & -0.005 & & 0.008 & & 0.042 & \\
\hline Household income $(0.125: 12.5)[£ 10,000]$ & -0.052 & $*$ & -0.005 & & 0.010 & & -0.015 & \\
\hline Household income squared + & 0.001 & & 0.000 & & -0.001 & & -0.001 & \\
\hline Level of education ( $0: 4)$ & 0.019 & & 0.078 & $* *$ & 0.069 & $* *$ & 0.064 & $* *$ \\
\hline Living in an urban area $(0: 1)$ & 0.034 & & -0.113 & $*$ & 0.063 & & 0.010 & \\
\hline Being a student $(0: 1)$ & -0.213 & $*$ & 0.094 & & 0.045 & & 0.189 & \\
\hline Living in a house $(0: 1)$ & 0.093 & $*$ & 0.011 & & 0.023 & & -0.081 & \\
\hline Cold weather benefit ( $0: 1)$ & 0.177 & $* *$ & & & & & & \\
\hline Having a mortgage $(0: 1)$ & 0.101 & $*$ & & & & & & \\
\hline Being a tenant $(0: 1)$ & 0.044 & & & & & & & \\
\hline Adj. $\mathbf{R}^{2}$ & 0.182 & & 0.230 & & 0.272 & & 0.051 & \\
\hline
\end{tabular}

Note:

${ }^{+}$Age and Income are included with their squares to allow for changes in their impact over the range of values without assuming a particular form of the relationship.

Table 3. Wald test statistics for location tests

\begin{tabular}{llcc}
\hline $\begin{array}{l}\text { Regional } \\
\text { Division }\end{array}$ & Regression & $\chi^{2}$ (d.o.f) & $\operatorname{Prob}>\chi^{2}$ \\
\hline Urban & Energy use reduction behaviour & $17.53(14)$ & 0.229 \\
& Environmental identity & $13.79(19)$ & 0.796 \\
& $\quad$ Concern for climate change & $12.12(18)$ & 0.841 \\
Note: $\quad$ (d.o.f.) indicate number of degrees of freedom. & & \\
\hline
\end{tabular}

Tests of the location variables were performed by re-running the energy use reduction behaviour, environmental identity, and concern for climate change analysis separately for urban and non-urban respondents. In this study urban is defined as areas with a population greater than 10,000. Wald tests were conducted comparing the regression results, and all of the comparisons were outside of the critical region, implying that any differences between urban and non-urban residents are not statistically significant (Table 3) (StataCorp, 2009). However, it 
was found that concern for climate change was a significant driver of behaviour for urban residents $(z=2.40)$, while it was not for non-urban residents $(\mathrm{z}=1.12)$.

Finally, the individual behaviours were each regressed using the same independent variables. However, the model explained much less variance when looking at the individual behaviours than when analysing the combined scale (Adj. $\mathrm{R}^{2}$ of $0.072 \rightarrow 0.105$ compared with 0.182 ), which supports the notion that the behaviours are related and form a common scale.

\subsection{Transport Mode Choice for Commuting to Work or College, or Going Grocery Shopping}

A smaller sub-sample was used for the travel mode choice analysis, including only those working or studying. The model accounted for $25.2 \%$ of the variance in transport mode choice as measured by adjusted $\mathrm{R}^{2}$ (Table 4 ). Positive attitudes towards cars were positively correlated with choosing more carbon intensive transport, as was living in a single dwelling house as opposed to a flat. People with higher incomes or further to travel chose more highly carbon-intense transport. Being a student tended to lower the use of carbon intense transport.

Similar effects were observed for travel to buy groceries, except that having greater education had a positive effect, and being a student was no longer significant. There was also an unexpected effect of greater concern for climate change being linked to higher carbon transport modes, though the effect was less than for attitudes to transport. Furthermore, greater knowledge and higher prioritisation of climate change, higher level of education, and being female all related to having less pro-car or more pro-public transport attitudes.

Table 4. Transport mode results

\begin{tabular}{|c|c|c|c|c|c|c|}
\hline \multirow{3}{*}{$\begin{array}{l}\text { Independent Variables } \\
\text { (Range) [Units] } \\
\text { Environmental identity } \quad(0: 10)\end{array}$} & \multicolumn{6}{|c|}{ Dependent variable $(n=1,016)$} \\
\hline & \multicolumn{2}{|c|}{$\begin{array}{l}\text { Transport mode: } \\
\text { Work/school }\end{array}$} & \multicolumn{2}{|c|}{$\begin{array}{l}\text { Transport mode: } \\
\text { Groceries }\end{array}$} & \multicolumn{2}{|c|}{$\begin{array}{l}\text { Attitude to transport } \\
\text { modes }\end{array}$} \\
\hline & 0.069 & & 0.004 & & & \\
\hline Attitude to climate change $(-1.9: 2)$ & 0.224 & & 0.439 & $* *$ & & \\
\hline Attitude to transport modes $(-19: 1.9)$ & 1.348 & $* *$ & 1.708 & $* *$ & & \\
\hline Revealed knowledge $\quad(-3: 15)$ & -0.003 & & -0.005 & & -0.027 & $* *$ \\
\hline Self-reported knowledge $\quad(-2: 2)$ & -0.089 & & -0.134 & & -0.048 & \\
\hline Prioritisation of climate change $\quad(0: 4)$ & -0.073 & & 0.050 & & -0.107 & $* *$ \\
\hline Age $\quad(16: 92)$ & -0.001 & & 0.062 & & 0.029 & $*$ \\
\hline Age squared + & 0.000 & & 0.000 & & 0.000 & * \\
\hline Female $\quad(0: 1)$ & -0.043 & & -0.210 & & -0.085 & $*$ \\
\hline Number of adults $(1: 4)$ & -0.183 & & -0.028 & & 0.038 & \\
\hline Number of children $\quad(0: 4)$ & 0.166 & & 0.172 & & -0.004 & \\
\hline Household income $\quad(0.125 \quad: \quad 12.5)$ & 0.217 & * & 0.335 & $* *$ & 0.049 & \\
\hline Household income squared+ & -0.019 & $*$ & -0.023 & $*$ & -0.002 & \\
\hline Level of education $\quad(0: 4)$ & 0.107 & & 0.181 & $* *$ & -0.050 & $* *$ \\
\hline Living in an urban area $(0: 1)$ & 0.258 & & 0.067 & & -0.117 & $* *$ \\
\hline Being a student $\quad(0: 1)$ & -0.739 & $*$ & 0.024 & & -0.212 & $*$ \\
\hline Living in a house $(0: 1)$ & 0.469 & $*$ & 0.765 & $* *$ & 0.135 & $* *$ \\
\hline $\begin{array}{l}\text { Inverse of miles to work/school/grocery } \\
\text { storet }(0.01: 1)\end{array}$ & -2.916 & $* *$ & 0.713 & $* *$ & & \\
\hline $\begin{array}{l}\text { Living in an area with high frequency bus } \\
\text { service }(7.5: 59.3)\end{array}$ & -0.006 & & -0.005 & & & \\
\hline
\end{tabular}




\begin{tabular}{lcc}
\hline Adj. $\mathbf{R}^{\mathbf{2}}$ & & 0.146 \\
Pseudo $\mathbf{R}^{2}$ & 0.252 & 0.259 \\
\hline
\end{tabular}

Notes:

${ }^{+}$Age and Income are included with their squares to allow for changes in their impact, e.g. consistent impact per year while of working age and no additional impact thereafter) without assuming a particular form of the relationship.

${ }^{\ddagger}$ Distance is included as its inverse. This supposes that travelling twice as far away will always have the same impact, rather than assuming that the impact of travelling one mile further is constant, which is more consistent with travel patterns.

When the model was applied to individual transport modes, it was generally able to predict a higher proportion of the variance: $49 \%$ for cycling/walking, $25.7 \%$ for using public transport, $11.6 \%$ for getting a lift and $33 \%$ for driving (Table 5). Being more pro-car had a significant positive impact on choosing to drive, but lowered the use of both public transport and walking/cycling. However, attitudes towards cars had no significant correlation with whether or not someone got a lift. Unexpectedly, having attitudes of greater concern about climate change was positively correlated with driving and negatively with taking the bus, however the effect was smaller than for attitudes towards cars. The likelihood of choosing driving as the primary mode of transport also increased with rising income, while being a student was only linked to a positive impact on the likelihood of walking/cycling.

Table 5. Individual transport mode results

\begin{tabular}{|c|c|c|c|c|}
\hline Mode & Positively significant variables & & Negatively significant vari & \\
\hline Walk/cycle & $\begin{array}{l}\text { Age } \\
\mathrm{p}<0.01 \text { ); } \\
\text { Being a student } \\
\mathrm{p}<0.01 \text { ); } \\
\text { Inverse of miles travelled } \\
\mathrm{p}<0.01 \text { ); }\end{array}$ & $\begin{array}{l}(\beta=0.19, \\
(\beta=1.38, \\
(\beta=4.85,\end{array}$ & $\begin{array}{l}\text { Attitude to transport mode } \\
\text { p }<0.01 \text { ); } \\
\text { Age squared } \\
\text { p }<0.01 \text { ); } \\
\text { Number of children } \\
\text { p }<0.01 \text { ); } \\
\text { House } \\
\text { p }<0.01 \text { ); }\end{array}$ & $\begin{array}{l}(\beta=-0.80, \\
(\beta=-0.00, \\
(\beta=-0.44, \\
(\beta=-0.82,\end{array}$ \\
\hline Public transport & $\begin{array}{l}\text { Age squared } \\
\mathrm{p}<0.01 \text { ); } \\
\text { Household income squared } \\
\mathrm{p}<0.05) ; \\
\text { High frequency buses } \\
\mathrm{p}<0.01 \text { ); }\end{array}$ & $\begin{array}{l}(\beta=0.00, \\
(\beta=0.02, \\
(\beta=0.03,\end{array}$ & $\begin{array}{l}\text { Attitude to climate change } \\
\mathrm{p}<0.05) \text {; } \\
\text { Attitude to transport mode } \\
\mathrm{p}<0.01 \text { ); } \\
\text { Age } \\
\mathrm{p}<0.01 \text { ); } \\
\text { Level of education } \\
\mathrm{p}<0.01 \text { ); } \\
\text { Inverse of miles travelled } \\
\mathrm{p}<0.01 \text { ); }\end{array}$ & $\begin{array}{l}(\beta=-0.43, \\
(\beta=-1.79, \\
(\beta=-0.23, \\
(\beta=-0.22, \\
(\beta=-2.86,\end{array}$ \\
\hline Multiple passenger & & & $\begin{array}{l}\text { Attitude to climate change } \\
p<0.05) \\
\text { Level of education } \quad(\beta=-\end{array}$ & $\begin{array}{l}(\beta=-0.62, \\
0.05)\end{array}$ \\
\hline Single driver & $\begin{array}{l}\text { Climate change attitude } \\
\mathrm{p}<0.01) \\
\text { Attitude to transport } \\
\mathrm{p}<0.01 \text { ); } \\
\text { Age } \\
\mathrm{p}<0.05) \text {; } \\
\text { Household income } \\
\mathrm{p}<0.05 \text { ); } \\
\text { Level of education } \\
\mathrm{p}<0.05) \text {; }\end{array}$ & $\begin{array}{l}(\beta=0.41, \\
(\beta=1.66, \\
(\beta=0.11, \\
(\beta=0.27, \\
(\beta=0.17,\end{array}$ & $\begin{array}{l}\text { Household income squared } \\
\mathrm{p}<0.01 \text { ); } \\
\text { Inverse of miles travelled } \\
\mathrm{p}<0.01 \text { ); } \\
\text { High frequency bus service } \\
\mathrm{p}<0.05 \text { ); }\end{array}$ & $\begin{array}{l}(\beta=-0.02, \\
(\beta=-1.99, \\
(\beta=0.01,\end{array}$ \\
\hline
\end{tabular}


The age of respondents was positively related to both walking/cycling and driving, but negatively related to using public transport. People living in an area with a more high frequency bus service were slightly more likely to take public transport, and less likely to drive. Distance travelled was highly correlated with both public transport and driving, while being highly negatively correlated with walking/cycling. Higher levels of education were significantly related to increased driving, and decreases in taking public transport and getting a lift. Finally, people living in a house, and those with more children in the household were less likely to walk or cycle.

\section{Discussion}

\subsection{Energy Use Reduction}

As expected, people who were more concerned about climate change were more likely to reduce their household energy use, which concurred with Poortinga et al. (2004) and Stern et al. (1995). People who had an environmental identity, were also more likely to participate in energy saving behaviours, also as anticipated (Sparks \& Shepherd, 1992).

The prioritisation placed by respondents on climate change was expected to have a direct effect on behaviour (Huddart-Kennedy et al., 2009; Whitmarsh \& O'Neill, 2010), however this study found that it only indirectly correlated with home energy use reduction through environmental identity and concern for climate change. The difference could be due to variable construction, as respondents were not directly asked to prioritise climate change relative to other issues. Prioritisation, as constructed here, could also be acting to mediate other determinants in a smaller number of cases where other factors conflict (Dijst et al., 2008), limiting its impact on the wider population.

Previous studies showed a positive impact of knowledge on behaviour (Grob, 1995), but no direct effect was found in this study. However, knowledge can also affect behaviour through identity and attitude (McCright, 2010), and this study found a link from knowledge to attitude, but not from knowledge to identity. Interestingly, self-reported knowledge of climate change did have a positive effect on behaviour, identity, and attitudes. This suggests that self-reported knowledge is a more important determinant than actual knowledge of climate change. This is possibly because knowledge in the absence of self-reported knowledge indicates uncertainty, which could make people less likely to act on what they know. However, it is important to note that the effects of revealed knowledge were still important and that the two variables were highly correlated (i.e. people who said they knew more generally did).

Environmental identity and concern for climate change were largely unimportant in choosing individual behaviours, despite being very important to the overall level of engagement. This suggests that how much you consider yourself to be environmental, or how concerned you are about the environment has little to say about which actions you will take, only that you are more likely to act.

Education had a positive effect on behaviour, which is consistent with some previous studies (Stead, 2007). The impact of household income was negative on behaviour, contrary to previous studies on reported behaviour, but in line with expected outcomes of actual energy use (Jones et al., 1999; Poortinga et al., 2004). These results further support the findings of Poortinga et al. (2004) that the level of education and level of income can have conflicting effects on behaviour while at the same time being linked. It was also interesting to see that income was not relevant to identity or attitudes, while education was. This suggests that though income and education are linked in their direct impact on behaviour, their effect on the psychological factors considered here are unrelated.

As anticipated, households with more children were less likely to reduce their energy use from everyday behaviours, particularly turning off the lights in unused rooms, or turning down the heat when going out (Poortinga et al., 2004). This could be because people want a warm and well lit home for their children to feel safe in, or because they have less time and/or other more pressing concerns. No effect was observed based on the number of adults in the house, in line with Whitmarsh and O'Neill (2010).

Tenants and people in flats were much less likely to hang their washing out to dry, likely for lack of space or not wanting to use communal areas. Women were also more likely to perform energy reduction behaviours, and exhibit concern about climate change, in line with previous studies (McCright, 2010; Paço \& Varejão, 2010).

Overall levels of engagement in energy use reduction were found to be similar between urban and non-urban residents, in line with previous findings for other types of environmental engagement (Huddart-Kennedy et al., 2009). However, it was found that concern for climate change is a more important factor for urban residents than for rural residents, suggesting that further research into the effect of location should consider how attitudes affect behaviours in different areas, rather than just considering whether the attitudes are similar, as is typically done 
(Huddart-Kennedy et al., 2009). To increase the information available, further studies could also follow the same population to generate panel data, which can yield more robust conclusions because it is possible to see what effect a change in a variable has on a person's behaviour (Tan et al., 2006). Panel data can thus offer further insight into what variables are most likely to change someone's behaviour, which may be a different, and perhaps more important, research question.

\subsection{Travel Mode Choice}

Contrary to energy use reduction behaviours, neither concern for climate change nor having an environmental identity were linked to the use of less carbon intensive modes of travel for commuting. Nor did they increase the likelihood of choosing one of the individual low carbon travel modes (such as walking or taking public transport) Murtagh et al. (2012) found that if people perceived a threat to their identity (e.g., as a motorist or a parent) there was reluctance to change behaviours. What their results demonstrate is that when it comes to travel choice behaviours in particular, there may be self-identities other than environmental identity that are important.

Further, Line et al. (2012) suggest that self-identity (image) is important in choosing to travel by car but these self-identities are not to do with environmental identity. This raises an interesting question of what happens when different self-identities compete. In this case, identities related to car ownership and motoring conflict with personal norms relating to climate change and environmental identity, as highlighted by the finding that prioritisation of climate change and being pro-car were opposed.

Interestingly, revealed knowledge of climate change was important in shifting attitudes towards public transport, while self-reported knowledge was not, in contrast to the importance of self-reported knowledge to attitudes to climate change. When considered with the impact of education on reducing pro-car attitudes, this suggests that education does have a role to play in changing travel mode decisions, though it is indirect. Other studies have also found knowledge plays a role in relation to intended transport behaviours in the context of climate change issues (Line et al., 2012).

The model offered the least explanation of why people get a lift to work, possibly because getting a lift is mostly related to whether a person is travelling the same direction as someone in their home or is on someone else's route, which are not captured in the study.

The relationship between age and transport mode did not follow the combined transport scale, rather people switched more to walking or driving as they got older. This may be due to a move from more communal to more solitary modes of transportation or a reflection of different living patterns at different ages. Previous work (Arnold, 2010) found a more direct relationship with older people more likely to drive than to take most other options transport options. Overall, there is scope for investigating the relationship between transport mode behaviours and life stage.

People were more likely to choose to use the bus if they lived near high frequency bus service routes, meaning that they do not need to plan what time they leave the house. Though proximity to high frequency bus service only had a small impact, it was an indirect measure of the datazone on average and not the respondent in particular. Its significance suggests this is an area which may have greater implications, and should be incorporated directly into future studies which include travel mode choices. Arnold (2010) concluded that policies aimed at structural change might be more effective than policies aimed at changing people's environmental values. The findings from the current analysis suggest that this may be true.

The underlying determinants of travel mode choice were attitudes towards travel mode directly (i.e. positive or negative opinions of the convenience and reliability of cars versus public transport), as well as demographic and structural variables such as income and distance travelled. This reinforces earlier findings (Line et al., 2012) that peoples' intention to use the car is at least in part related to positive attitudes towards cars and negative attitudes towards public transport. Arnold (2010) found a similar relationship between positive attitudes to cars and use of cars.

\subsection{Policy Implications}

This study has shown that energy use reduction behaviours and travel mode choices have both demographic and psychological determining factors, and suggests a hierarchical nature of some of the effects. Notably there are some important differences in influences on energy use behaviours as opposed to transport use behaviours. In particular having an environmental identity was found to be an important driver of household energy use reduction, as was concern for climate change indirectly, but neither affected choice of transportation mode. Knowledge also had a greater effect on household energy use reduction than on transport behaviours. Further, energy use reduction behaviours were best understood as a group of behaviours rather than individually while 
the opposite was true for the transport behaviours.

In terms of energy use behaviours, this means there is a role for information programmes, and they should seek to promote a range of behaviours for increased effect. This supports the current government strategy to engage individuals in energy use reduction through information and positive encouragement and not just regulation change (Scottish Government, 2010). Contrastingly transport mode decisions are best explained when looking at transport modes individually, and so promotion of less carbon intense modes of transportation should encourage particular travel modes explicitly rather than promoting "low carbon" travel in general. This means seeking to change attitudes directly related to the individual modes and their convenience rather than focusing on the implications for the environment. Policy attempting to change travel mode decisions also needs to affect structural change to make travel by public transport more desirable. One important finding is that appealing to an individual's environmental identity with messages about "green" behaviours may be more effective when targeting energy use behaviours in the home, than when focusing on travel behaviours.

The results of this new analysis showed that attitudinal factors contribute in an important manner to energy related behaviour. This study also supports recommendations that attempts at behavioural intervention through attitudes cannot be taken in isolation from other factors (House of Lords, 2011), and that information targeting campaigns are likely to be more effective when tailored to the target audience (Southerton et al., 2011). This analysis helps identify factors linked to individual behaviours, and thus could be used to help ensure the right people are targeted by the right type of information. It also offers further support to conclusions that attitudes lead to behaviours, and thus strengthens the case for seeking to influence attitudes as a viable means of affecting behaviour (Davidson et al., 2009). These findings add to existing literature on environmental behaviour and provide more rigorous analysis of available data in Scotland than previously existed. Greater information on the causal factors of behaviour can help policy makers be more effective at promoting behavioural change to encourage reduction of GHG emissions. The findings suggest that using 'green' messaging will likely help encourage behavioural change in home energy, but contribute little to encouraging change in travel mode decisions.

\section{Acknowledgements}

This research was undertaken within the Scottish Government Rural Affairs and the Environment Portfolio Strategic Research Programme 2011-2016, Theme Four 'A rural economy resilient to global and local change'. For more information please see: http://www.scotland.gov.uk/Topics/Research/About/EBAR/StrategicResearch/future-research-strategy/Themes/T hemesIntro

\section{References}

Ajzen, I. (1988). Attitudes, Personality and Behavior. Buckinham: Open University Press.

Ajzen, I. (1991). The theory of planned behavior. Organizational behavior and human decision processes, 50(2), 179-211. http://dx.doi.org/10.1016/0749-5978(91)90020-T

Armitage, C. J., \& Conner, M. (2001). Efficacy of the theory of planned behaviour: A meta - analytic review. British journal of social psychology, 40(4), 471-499. http://dx.doi.org/10.1348/014466601164939

Arnold, S. (2010). Environmental Decision Making and Behaviours: How do People Choose how to Travel to Work? Working Paper. Bath, UK: Department of Economics, University of Bath.

Berenguer, J., Corraliza, J. A., \& Martín, R. (2005). Rural-Urban Differences in Environmental Concern, Attitudes, and Actions. European Journal of Psychological Assessment, 21(2), 128. http://dx.doi.org/10.1027/1015-5759.21.2.128

Davidson, S., Martin, C., \& Treanor, S. (2009). Scottish Environmental Attitudes and Behaviours Survey 2008. Edinburgh, UK: Scottish Government Social Research.

DECC. (2013). DECC public attitudes tracker Wave 5. Summary of key findings. Department of Energy and Climate Change, 2012. UK Emissions Statistics. DECC, London. Retrieved from http://www.decc.gov.uk/en/content/cms/statistics/climate_stats/gg_emissions/uk_emissions/uk_emissions.as $\mathrm{px}$

Fielding, K. S., McDonald, R., \& Louis, W. R. (2008). Theory of Planned Behaviour, identity and intentions to engage in environmental activism. Journal of Environmental Psychology, 28, 318-326. http://dx.doi.org/10.1016/j.jenvp.2008.03.003 
Fishbein, M., \& Ajzen, I. (1975). Belief, Attitude, Intention, and Behavior: An Introduction to Theory and Research. Reading, MA: Addison-Wesley.

Fujii, S., \& Gärling, T. (2003). Application of attitude theory for improved predictive accuracy of stated preference methods in travel demand analysis. Transportation Research Part A, 37, 389-402. http://dx.doi.org/10.1016/S0965-8564(02)00032-0

Grob, A. (1995). A structural model of environmental attitudes and behaviour. Journal of Environmental Psychology, 15, 209-220. http://dx.doi.org/10.1016/0272-4944(95)90004-7

Guagano, G. A., Stern, P. C., \& Dietz, T. (1995). Influences on attitude-behavior relationships: A natural experiment with curbside recycling. Environment and Behavior, 27, 699-718. http://dx.doi.org/10.1177/0013916595275005

House of Lords. (2011). Behaviour Change-Science and Technology Select Committee 2nd Report of Session 2010-12. London, UK: Authority of the House of Lords.

Huddart-Kennedy, E., Beckley, T. M., McFarlane, B. L., \& Nadeau, S. (2009). Rural-urban differences in

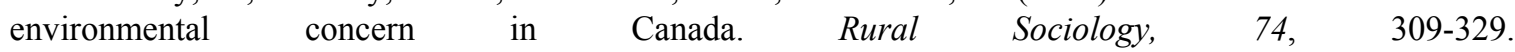
http://dx.doi.org/10.1526/003601109789037268

Jones, R. E., Fly, J. M., \& Cordell, H. K. (1999). How green is my valley? Tracking rural and urban environmentalism in the southern Appalachian ecoregion. Rural Sociology, 64, 482-499. http://dx.doi.org/10.1111/j.1549-0831.1999.tb00363.x

Line, T., Chatterjee, K., \& Lyons, G. (2012). Applying behavioural theories to studying the influence of climate change on young people's future travel intentions. Transportation Research Part D, 17, 270-276. http://dx.doi.org/10.1016/j.trd.2011.12.004

Lingyun, M., Rui, N., Hualong, L., \& Xiaohua, L. (2011). Empirical research of social norms affecting urban residents low carbon energy consumption behavior. Energy Procedia, 5, 229-234. http://dx.doi.org/10.1016/j.egypro.2011.03.041

Lynn, P., \& Longhi, S. (2011). Environmental attitudes and behaviour: who cares about climate change? In S. L. Garrington (Ed.), Understanding Society: early findings from the first wave of the UK's household longitudinal study (pp. 109-116). Colchester, UK: Institute for Social and Economic Research: University of Essex.

McCright, A. M. (2010). The effects of gender on climate change knowledge and concern in the American public. Population \& Environment, 32, 66-87. http://dx.doi.org/10.1007/s11111-010-0113-1

Murtagh, N., Gatersleben, B., \& Uzzell, D. (2012). Self-identity threat and resistance to change: Evidence from regular travel behaviour. Journal of Environmental Psychology, 32, 318-326. http://dx.doi.org/10.1016/j.jenvp.2012.05.008

Neuman, K. (1986). Personal values and commitment to energy conservation. Environment and Behavior, 18, 53-74. http://dx.doi.org/10.1177/0013916586181003

Paço, A. D., \& Varejão, L. (2010). Factors affecting energy saving behaviour: a prospective research. Journal of Environmental Planning and Management, 53, 963-976. http://dx.doi.org/10.1080/09640568.2010.495489

Palmer, J., \& Cooper, I. (2011). Great Britain's housing energy fact file. London: Department of Energy and Climate Change (DECC).

Parry, M., Canziani, O., Palutikof, J., \& Co-authors. (2007). Technical Summary. In IPCC, M. Parry, O. Canziani, J. Palutikof, P. v. Linden, \& C. Hanson (Eds.), Climate Change 2007: Impacts, Adaptation and Vulnerability. Contribution of Working Group II to the Fourth Assessment Report of the Intergovernmental Panel on Climate Change (pp. 23-78). Cambridge, UK: Cambridge University Press.

Poortinga, W., Steg, L., \& Vlek, C. (2004). Values, environmental concern, and environmental behavior: A study into household energy use. Environment and Behavior, 36, 70-93. http://dx.doi.org/10.1177/0013916503251466

Scottish Government (2010). Low Carbon Scotland: Public Engagement Strategy. Scottish Government, Edinburgh.

Scottish Government. (2011). Scottish Household Survey-Survey Review 2010. Retrieved November 2011, from http://www.scotland.gov.uk/Topics/Statistics/16002/SurveyReview2010 
Scottish, Parliament. (2009). Climate Change (Scotland) Act 2009 (asp 12). Edinburgh, UK: The Scottish Parliament.

Sheppard, B. H., Hartwick, J., \& Warshaw, P. R. (1988). The Theory of Reasoned Action: A meta-analysis of past research with recommendations for modifications and future research. Journal of Consumer Research, 15, 325-343. http://dx.doi.org/10.1086/209170

Southerton, D., McMeekin, A., \& Evans, D. (2011). International Review of Behaviour Change Initiatives. Edinburgh, UK: Scottish Government Social Research.

Sparks, P., \& Shepherd, R. (1992). Self-identity and the Theory of Planned Behavior: Assessing the role of identification with "Green Consumerism". Social Psychology Quarterly, 55, 388-399. http://dx.doi.org/10.2307/2786955

StataCorp. (2009). Stata Multivariate Statistics Reference Manual Release 11. College Station, TX: StataCorp LP.

Stead, D. (2007). Transport energy efficiency in Europe: Temporal and geographical trends and prospects. Journal of Transport Geography, 15, 343-353. http://dx.doi.org/10.1016/j.jtrangeo.2006.11.009

Stern, N. (2006). The Economics of Climate Change: The Stern Review. Cambridge: Cambridge University Press.

Stern, P. C. (2000). Toward a coherent theory of environmentally significant behavior. Journal of Social Issues, 56, 407-424. http://dx.doi.org/10.1111/0022-4537.00175

Stern, P. C., Dietz, T., \& Guagano, G. A. (1995). The New Ecological Paradigm in social-psychological context. Environment and Behavior, 27, 723-743. http://dx.doi.org/10.1177/0013916595276001

Tan, P. N., Steinbach, M., \& Kumar, V. (2006). Introduction to Data Mining. Boston, Massachusetts: Addison-Wesley.

Whitmarsh, L., \& O'Neill, S. (2010). Green identity, green living? The role of pro-environmental self-identity in determining consistency across diverse pro-environmental behaviours. Journal of Environmental Psychology, 30, 305-314. http://dx.doi.org/10.1016/j.jenvp.2010.01.003

Whitmarsh, L., Seyfang, G., \& O’Neill, S. (2011). Public engagement with carbon and climate change: To what extent is the public 'carbon capable'? Global Environmental Change, 21, 56-65. http://dx.doi.org/10.1016/j.gloenvcha.2010.07.011

\section{Notes}

Note 1. Which include methane, nitrous oxide, and hydrofluorocarbons.

Note 2. Identity differs from TPB's use of subjective norms. The latter relates to the views of close relations, e.g. parents who may not be likeminded, whereas identity references a group holding shared values.

Note 3. Although there were demographic differences between respondents who were kept and those who were removed, probit analysis revealed only one significant variable for non-completion: education $(P>|z|=0.000)$, and the overall explanatory ability was low (Pseudo $\mathrm{R}^{2}=0.0369$ ).

Note 4. Payable to certain welfare benefit recipients when local temperature is either recorded as, or forecast to be, an average of zero degrees Celsius or below over 7 consecutive days.

\section{Copyrights}

Copyright for this article is retained by the author(s), with first publication rights granted to the journal.

This is an open-access article distributed under the terms and conditions of the Creative Commons Attribution license (http://creativecommons.org/licenses/by/3.0/). 